time and choice latency in short-term memory experiments have been shown to increase under marihuana (Clark et al, 1970; Darley et al, 1973). Additionally, $\Delta^{9}$-THC is known to increase the proportion of longer latency incorrect matching trials as compared to nondrug matching performance.

On the other hand, if choice response speed is assumed to reflect a S's retrieval criterion for acceptance of an incorrect alternative from memory, as may be inferred from some signal detection theories of short-term memory (e.g., Murdock, 1968), then choice speed would be expected to increase under $\Delta^{9}$-THC. This is because Abel (1971a b), among others, has shown that marihuana produces a lowered criterion value in recognition memory tasks. The fact that choice speed was unaltered while matching accuracy was decreased by $\Delta^{9}$-THC in the present experiment mitigates the likelihood of a drug-produced retrieval failure and tends, instead, to implicate an impairment of acquisition-storage processes.

\section{REFERENCES}

Abel, E. L. Marihuana and memory: Acquisition or retrieval? Science, 1971a, 173, 1038-1040.

Abel, E. L. Retrievel of information after use of marihuana. Nature, $1971 \mathrm{~b}, 231,58$.

Clark, T. B., Hughes, R., \& Nakashima, E. N. Behavioral effects of marihuana: Experimental studies. Archives of General Psychiatry, 1970, 23, 193-198.

Darley, C. F., Tinklenberg, J. R., Hollister, T. E., \& Atkinson, R. C. Marihuana and retrieval from short-term memory. Psychopharmacologia, 1973, 29, 231-238.
Ferraro, D. $P$ Current research in marihuana: Effects of $\Delta^{9}$-trans-tetrahydrocannabinol on simple and complex learned behavior in animals. In M. Lewis (Ed.), Current research in marihuana. New York: Academic Press, 1972.

Ferraro, D. P., \& Grilly, D. M. Tolerance to $\Delta^{9}$-tetrahydrccannabinol under delayed matching-to-sample tasks in chimpanzees: Effects of delay length. Psychonomic Science, 1972, 29, 329

Ferraro, D. P., \& Grilly, D. M. Lack of tolerance to $\Delta^{9}$-tetrahydrocannabinol in chimpanzees. Science, 1973,179 490-492.

Ferraro, D. P., Grilly, D. M., \& Grisham, M. G. $\Delta^{9}$-tetrahydrocannabinol and delayed matching to sample in chimpanzees. In J. M. Singh (Ed.), Drug addiction. Vol. III. New York: Futura, 1973 (in press).

Grilly, D. M., Ferraro, D. P., \& Marriott, R. G. Long-term interactions of marihuana and behavior in chimpanzees. Nature, 1973, 242, 119-120.

Jarrard, L. E., \& Moise, S. D. Short-term memory in the monkey. In L. E. Jarrard (Ed.), Cognitive processes in nonhuman primates. New York: Academic Press, 1971.

Murdock, B. B. Response latencies in short-term memory. Quarterly Journal of Experimental Psychology, 1968, 20, 79-82.

Milner, A. D., \& Ettlinger, G. Response latencies in go, no-go discrimination performance by monkeys. Neuropsychologia $1972,10,375-378$.

Stone, G. C. Response latencies in matching and oddity performance: Effects of format, stimulus, and demand variables. Perceptual \& Motor Skills, 1969, 29, 219-232.

(Received for publication August 20, 1973.)

\title{
Rats barpress in order to change the rate at which they are fed*
}

\author{
GEORGE W. LAWTON \\ University of Minnesota, Minneapolis, Minn. 55455 \\ and \\ STEPHEN WINOKUR \\ Texas Christian University, Fort Worth, Tex. 76129
}

Four rats were fed irregularly but on the average of once every $3 \mathrm{~min}$. If a rat pressed a bar, the average interfeeding interval dropped to once every $30 \mathrm{sec}$. All four rats learned to barpress. When barpresses no longer changed the average interfeeding interval, the rats tended not to press. A reintroduction of the relation between barpressing and reduction of the interfeeding interval generated renewed barpressing.

Herrnstein \& Hineline (1966) and Herrnstein (1969) have argued that the principal reinforcement in avoidance learning is the reduction of the temporal frequency (rate) of aversive events. Herrnstein \& Hineline (1966) arranged a situation in which rats were shocked irregularly but with a constant average rate irrespective of their behavior. If a rat barpressed, the average rate of shocks received by him would decrease

\footnotetext{
*We thank Kenneth MacCorquodale for encouragement and the loan of equipment and the Texas Christian University Research Foundation for Grant PS 6977 to S.W., which partially supported the conduct of the research reported here.
}

for a brief period of time following the barpress until the delivery of the next shock, then the rate of shock presentations would be restored to its former level. Rats learned to barpress, and barpressing rates were shown to be dependent upon response-contingent percentage reduction in shock rate.

Fantino (1969) had argued that pigeons responding on concurrent chain schedules of positive reinforcement will prefer the key which leads to more immediate reinforcements. Herrnstein $(1961,1964)$ had argued that stimuli associated with greater rates of reinforcement will be better conditioned reinforcers than stimuli associated with lesser rates of reinforcement.

A general hypothesis emerges from the foregoing: animals will respond to receive a higher rate of positive reinforcers or a lower rate of aversive events, or the stimuli associated with them. In the standard operant conditioning situation, a rat receives no reinforcers when he does not press a bar, and receives a reinforcer each time he does press. This situation is merely one point on a continuum of infinitely many possible relations between rate of reinforcement (or aversive stimulation) prior to instrumental behavior and rate of reinforcement (or aversive stimulation) following a response. Such an instrumental conditioning space has been proposed by Seligman, Maier, \& Solomon (1971) and Catania (1971). In the traditional view, temporal contiguity between a 


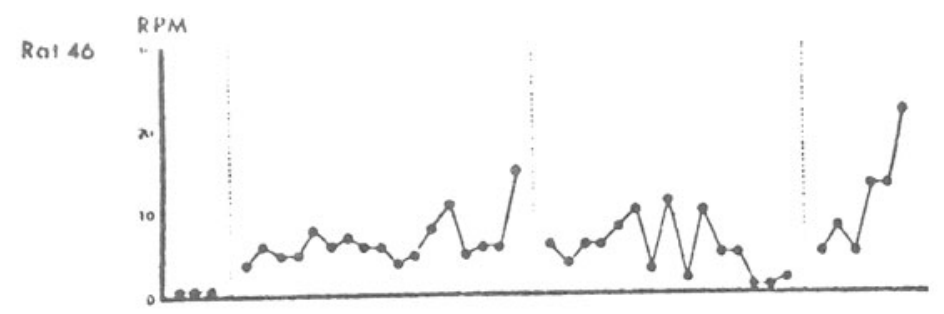

Fig. 1. Response rates of Rats 45 and 49

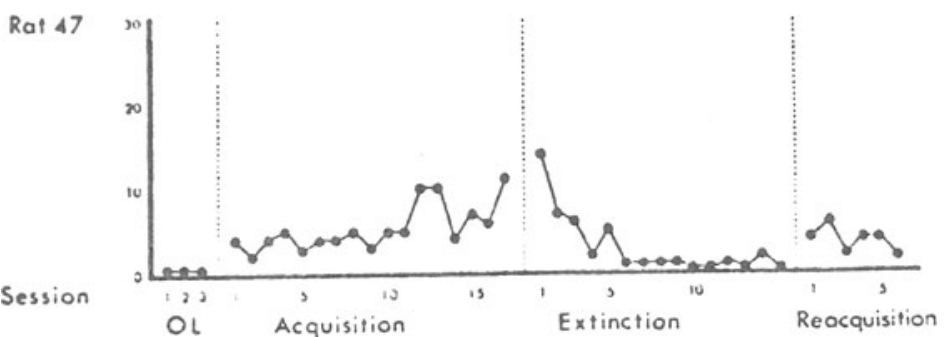
on each day of the experiment.

response and reinforcement is necessary and sufficient for instrumental learning to occur. Premack (1965) has argued. against this view, and demonstrated that temporal contiguity is not sufficient for conditioning. The present view holds that, ceteris paribus, temporal contiguity between response and reinforcer may be optimal for conditioning, but it is not necessary. Rather, if the rate (or probability) of reinforcement, given an occurrence of a response, is higher than the rate (or probability) of reinforcement given nonoccurrence of the response. then conditioning should occur. The experiment reported here sought to test this hypothesis.

\section{METHOD}

\section{Subjects}

Four naive male albino rats, obtained from Simonson Laboratories, were 90 days old at the beginning of the experiment. They were maintained at $80 \%$ of their ad lib weights by controlled feedings of Purina Lab Animal Chow after each 50 -min daily session. Water was available in the rats' home cages at all times.

\section{Apparatus}

A Foringer rat chamber with a T-shaped bar mounted 2 in. to the left of the food cup was used. The force required to operate the microswitch attached to the bar was $15 \mathrm{~g}$. The bar was mounted 2 in. above the grid floor of the box and 2 in. from the left wall. The floor plan of the chamber was about $8 \times 8$ in., and the bar and food cup were mounted on the front wall of the chamber. Electromagnetic programming and recording equipment was located in a room adjacent to that housing the chamber.

\section{Procedure}

For 2 consecutive days, the rats were adapted to the chamber which had the bar removed from it. Then, for 3 days, operant levels of barpressing were determined. The bars were reinserted into the chambers and presses were recorded, but had no programmed consequences.

During the acquisition phase of the experiment, a VT 3-min and a VT 30-sec tape ran concurrently. The VT 3-min tape caused food to drop into the food cup at irregular intervals, with mean interfood interval $=3 \mathrm{~min}$, range $=7.5-352.5 \mathrm{sec}$. Food deliveries occurred irrespective of the rats' behavior. If a rat pressed the bar, control of food deliveries was switched to the VT 30-sec tape. The VT 30-sec tape contained intervals with mean $=30 \mathrm{sec}$ and range $=7.5-52.5 \mathrm{sec}$. Once food was delivered by the VT 30-sec tape, control was returned to the VT 3-min tape. Barpressing while the VT 30-sec tape was running had no programmed consequences but was recorded. Both tapes dispensed a single 90-mg P. J. Noyes Rat Food Pellet for each food presentation. The acquisition phase of the experiment lasted 17 days.

During the extinction phase of the experiment, barpressing had no programmed consequences but was recorded. The VT 3-min tape dispensed food during the extinction phase for Rats 45 and 49 , whereas the VT $30-\mathrm{sec}$ tape dispensed food during the extinction phase for Rats 46 and 47 . The extinction phase had a duration of 15 days.

The extinction phase was followed by a reacquisition phase which lasted 5 days for Rat 45 and 6 days for Rats 46, 47, and 49. The procedure in effect during the reacquisition phase was the same as that in effect during the acquisition phase of the experiment.

\section{RESULTS AND DISCUSSION}

Figures 1 and 2 depict the response rates of each rat on each day of the experiment. It may be observed that little responding occurred during the operant level phase of the experiment. Rats 45, 46, 47, and 49 emitted, respectively, 49,22, 4, and 36 barpresses during the 3 days. The programmed relationship between barpressing and tape changing was immediately effective. On the first day of the acquisition phase, Rats $45,46,47$, and 49 emitted 168, 200, 190, and 401 responses, respectively. Both extinction procedures, i.e., with the VT 3-min tape dispensing food or with the VT 30-sec tape dispensing food, were effective. Rats extinguished while the VT 3-min tape dispensed food emitted 980 and 188 barpresses in the case of Rat 45 , and 570 and 67 in the case of Rat 49 , on the first and last days of the extinction phase, respectively. Rats extinguished while the VT 30-sec tape dispensed food emitted 298 and 101 barpresses in the case of Rat 46, and 701 and 52 responses in the case of Rat 47 , on the first and last days of the extinction phase, respectively. Reacquisition was extremely rapid for all Ss. The numbers of responses emitted on the last day of the extinction phase and the first day of the reacquisition phase were 188 and 697 for 


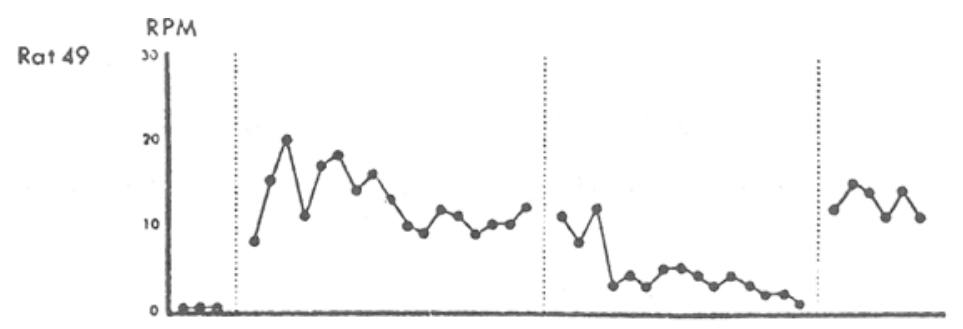

Fig. 2. Response rates of Rats 46 and 47 on each day of the experiment.

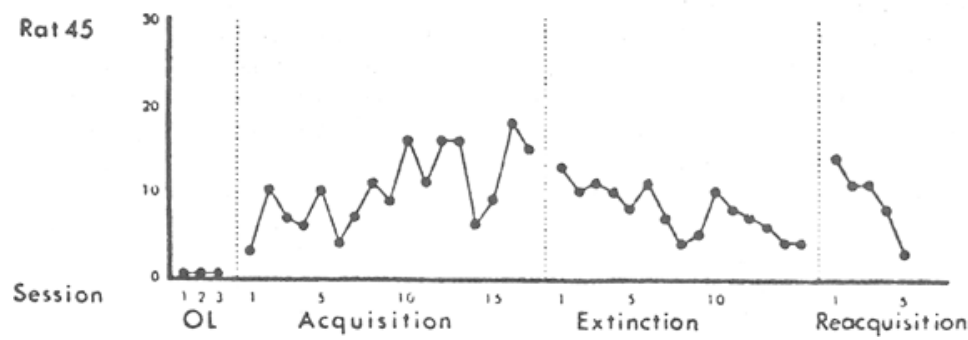

Rat 45, 101 and 275 for Rat 46, 52 and 269 for Rat 47, and 67 and 625 for Rat 49 .

These results suggest that the rats in this experiment barpressed in order to receive higher rates of food delivery. The data from the extinction phase of the experiment contradict the suggestion that these rats acquired the barpressing response via adventitious reinforcement. If barpressing were a superstitious behavior (Skinner, 1948) acquired and maintained by barpressing's being "accidentally" followed by food deliveries, then Rats 46 and 47 who were extinguished while the VT 30 -sec tape governed food presentations should not have tended to cease barpressing. If they were to do so, they should not do so as rapidly as did Rats 45 and 49 . However, the data presented here show that both sets of rats tended to cease barpressing to comparable degrees and with comparable speeds. The reinstatement of the conditions of the acquisition phase in the reacquisition phase produced extremely rapid increases in the rates of barpressing of all of the rats in this experiment. This development would not be expected if barpressing were maintained by adventitious reinforcement.

It might be argued that this experiment merely demonstrates conditioning of responding with delayed reinforcement. This argument may be seen to be invalid in light of the following considerations. If delayed reinforcement caused barpressing during the acquisition and reacquisition phases of this experiment, then delayed reinforcement should have maintained barpressing during the extinction phase of the experiment. These conclusions are supported by studies of delayed reinforcement reported by Ferster (1953).

In Ferster's Experiment V, four pigeons learned to respond on a two-component chain schedule of reinforcement whose initial component was accompained by a red keylight and whose terminal component was accompanied by a blue keylight. Then the contingency between pecking the blue key and the

operation of the feeder was removed, i.e., the feeder operated $1 \mathrm{~min}$ after the onset of the blue keylight irrespective of whether the birds pecked the blue key. Thus the birds pecked the red key with a delay of reinforcement of $1 \mathrm{~min}$. Rates of pecking the red key remained stable. Ferster's Experiment $V$ and his Experiments I-IV showed that responding was maintained in pigeons conditioned with delayed reinforcement. In the present experiment, the noncontingent feeder operations during the extinction procedure reduced response rates. This supports the agrument that the procedure in effect during the acquisition and reacquisition phases of the experiment was not merely one of conditioning with a delay of reinforcement, but one which showed that rats respond in order to change the rate at which they are fed.

\section{REFERENCES}

Catania, A. C. Elicitation, reinforcement, and stimulus control. In Robert Glaser (Ed.), The nature of reinforcement. New York: Academic Press, 1971. Pp. 196-220.

Fantino, E. Conditioned reinforcement, choice, and the psychological distance to reward. In D. P. Hendry (Ed.), Conditioned reinforcement. Homewood, Ill: Dorsey Press, 1969. Pp. 163-191.

Ferster, C. B. Sustained behavior under delayed reinforcement. Journal of Experimental Psychology, 1953, 45, 218-224.

Herrnstein, R. J. Relative and absolute strength of response as a function of frequency of reinforcement. Journal of the Experimental Analysis of Behavior, 1961, 4, 267-272.

Herrnstein, $R$. J. Secondary reinforcement and the rate of primary reinforcement. Journal of the Experimental Analysis of Behavior, 1964, 7, 27-36.

Herrnstein, R. J. Method and theory in the study of avoidance. Psychological Review, 1969, 76, 49-69.

Herrnstein, R. J., \& Hineline, P. N. Negative reinforcement as shock frequency reduction. Journal of the Experimental Analysis of Behavior, 1966, 9, 421-430.

Premack, D. Reinforcement theory. In D. Levine (Ed.), Nebraska symposium on motivation. Lincoln: University of Nebraska Press, 1965. Pp. 123-180.

Seligman, M. E. P., Maier, S. F., \& Solomon, R. L. Unpredictable and uncontrollable aversive events. In F. R. Brush (Ed.), Aversive conditioning and learning. New York: Academic Press, 1971. Pp. 347-400.

Skinner, B. F. Superstition in the pigeon. Journal of Experimental Psychology, 1948, 38, 168-172.

(Received for publication September 10, 1973.) 